\title{
Predictors of adherence to a physical activity counseling intervention delivered by exercise physiologists: secondary analysis of the $\mathrm{NewCOACH}$ trial data
}

This article was published in the following Dove Press journal:

Patient Preference and Adherence

\author{
Natalie A Johnson ${ }^{1-4}$ \\ Ben Ewald ${ }^{1-4}$ \\ Ronald C Plotnikoff ${ }^{3}$ \\ Fiona G Stacey ${ }^{1-4}$ \\ Wendy J Brown ${ }^{5}$ \\ Mark Jones ${ }^{1,4}$ \\ Elizabeth G Holliday ${ }^{1,4}$ \\ Erica $L$ James ${ }^{1-4}$ \\ 'School of Medicine and Public \\ Health, Faculty of Health and \\ Medicine, University of Newcastle, \\ Callaghan, NSW, Australia; ${ }^{2}$ Priority \\ Research Centre in Health Behaviour, \\ University of Newcastle, NSW, \\ Australia; ${ }^{3}$ Priority Research Centre \\ in Physical Activity and Nutrition, \\ University of Newcastle, NSW, \\ Australia; ${ }^{4}$ Hunter Medical Research \\ Institute, New Lambton Heights, NSW, \\ Australia; ${ }^{5} \mathrm{Centre}$ for Research on \\ Exercise, Physical Activity and Health, \\ School of Human Movement and \\ Nutrition Sciences, The University of \\ Queensland, Brisbane, QLD, Australia
}

Correspondence: Natalie A Johnson School of Medicine and Public Health, Faculty of Health and Medicine, University of Newcastle, University Drive, Callaghan, NSW, 2308, Australia

Tel +6I 240420552

Fax +6I 240420044

Email natalie.johnson@newcastle.edu.au
Background: General practitioners (GPs) cite time as a barrier to physical activity counseling. An alternative for time-poor GPs in Australia is the referral of insufficiently active patients to exercise physiologists (EPs). As data on the predictors of adherence to physical activity counseling interventions are limited, this study aimed to identify the sociodemographic, medical, health, and psychological characteristics of insufficiently active primary care patients who adhered to a physical activity counseling intervention delivered by EPs.

Methods: This secondary analysis of data from the NewCOACH randomized trial used logistic regression to identify predictors of adherence, defined as patient participation in at least four of the five physical activity counseling sessions. EPs provided information about the number of sessions, while other potential predictors were obtained from the self-administered baseline questionnaire and medical summary sheets provided by the GPs.

Results: Of the 132 patients referred to an EP, 102 (77\%) were adherent: 91 (69\%) and eleven $(8.3 \%)$ participated in all, or all but one, of the sessions, respectively. Of the remainder, seven $(5.3 \%)$ patients participated in three sessions, seven $(5.3 \%)$ participated in two sessions, five $(3.8 \%)$ participated in one session, and eleven $(8.3 \%)$ did not participate in any session. The odds of being adherent were 5.84 (95\% CI 1.46-23.4, $P \leq 0.05)$ times higher among retired participants than in those who were not in paid employment. The odds of being adherent 1) increased as the positive outcome expectation score increased (OR 1.89, 95\% CI 1.12-3.18, $P \leq 0.05$ ) and 2) decreased as the duration (days) between referral and the initial counseling session increased (OR 0.95, 95\% CI 0.92-0.98, $P<0.01$ ).

Conclusion: More than three quarters of the patients participated in all, or all but one, of the sessions. Being retired, positive outcome expectations, and having a shorter wait between referral and the initial appointment predicted adherence.

Keywords: insufficiently active, adherence, predictors, primary care, exercise physiologist, patients

\section{Background}

Increasing physical activity levels is a global health priority. ${ }^{1}$ Primary care-based physical activity promotion has been shown to increase self-reported physical activity over at least 12 months, ${ }^{2}$ but it is not well implemented: only $36.3 \%$ of adult Americans who received health care in 2012 reported being told to increase their physical activity or exercise, ${ }^{3}$ and only $9.2 \%$ of patients attending general practices in Australia recalled being advised to increase their physical activity. ${ }^{4}$ 
General practitioners (GPs) commonly cite lack of time as a barrier to physical activity counseling. ${ }^{5,6}$ One alternative for time-poor GPs is the referral of insufficiently active patients to an exercise service. In the UK, for example, Exercise Referral Schemes have been used since the early 1990s and typically involve the referral of primary care patients to supervised group-based exercise in a gym or leisure center over a 12-week period (the duration varies from 8 weeks to 26 weeks). ${ }^{7}$ A recent evaluation of one scheme, implemented in accordance with best practice recommendations developed by the National Institute for Health and Clinical Excellence, ${ }^{8}$ showed a positive effect on a range of health outcomes among the patients who completed the program. ${ }^{9}$ However, only $47 \%$ of patients completed the program, which is consistent with the results of a review showing the pooled level of adherence to Exercise Referral Schemes to be $43 \%$ (95\% CI 32\%-54\%). ${ }^{10}$

In Australia, GPs can refer insufficiently active patients to accredited exercise physiologists (EPs). ${ }^{11}$ These are allied health professionals who specialize in exercise prescription for persons at risk of developing, or have existing, medical conditions and injuries. ${ }^{11-13}$ Their scope of practice includes the provision of "advice and support for lifestyle modification with a strong focus on achieving behavioral change". ${ }^{13}$ While we have recently demonstrated that physical activity counseling by EPs is effective, adherence to the counseling intervention was not universal. ${ }^{14}$ To our knowledge, there are no data regarding the predictors of patient adherence to physical activity counseling interventions following referral from the primary care setting. Accordingly, the aim of this study was to identify the sociodemographic, medical, health, and psychological characteristics of insufficiently active primary care patients who adhered to a physical activity counseling intervention delivered by EPs.

\section{Methods Study design}

This is a secondary analysis of data collected in a three-arm pragmatic randomized trial testing the effect of counseling by EPs on physical activity among insufficiently active primary care patients. As described elsewhere, ${ }^{15} 203$ insufficiently active $(<7,000$ steps/day) primary care patients were randomly allocated to 1) five face-to-face counseling sessions with an EP, 2) one face-to-face counseling session followed by four telephone calls with an EP, or 3) a generic mailed physical activity brochure (usual care). The counseling was delivered by EPs who had undertaken 5 hours of study-specific training covering the importance of behavior change theory (specifically, Bandura's Social Cognitive Theory) and on how to operationalize theoretical constructs that have been shown to promote physical activity among adults (self-efficacy, outcome expectations, social support, perceived physical environment, and goal setting) $)^{16,17}$ using a patient-centered approach. There was no attempt to standardize the intervention and its delivery across participants, EPs, or geographic location. Accordingly, the behavior change counseling was applied flexibly based on the EPs' professional judgment of the participant's motivational readiness to change, physical activity preferences, capability, and medical limitations if present. Counseling sessions were provided at no cost to participants. No other incentives were used to encourage participants to adhere to the counseling intervention or to increase their physical activity level. All participants provided written informed consent, and the study was conducted in accordance with the Declaration of Helsinki ${ }^{18}$ and approved by the University of Newcastle's Human Research Ethics Committee (H-2011-0063).

\section{Participants}

The study participants were adult ( $\geq 18$ years) patients recruited from primary care clinics in Newcastle and Sydney, New South Wales, Australia from 2011 to 2014 who: 1) had regular access to a telephone, 2) could read and write in English and planned to live in the defined geographic recruitment area for the following 12 months, 3) were not too frail or disabled to begin an unsupervised exercise program (completed the Timed Up and Go 3 meter test in $<20$ seconds), 4) were deemed insufficiently active by 1 week of pedometry (achieved $\leq 7,000$ steps per day on average), and 5) had been randomly allocated to receive physical activity counseling by an EP (trial participants randomly allocated to receive usual care were excluded from the present study).

\section{Adherence}

The number of counseling sessions each patient engaged in was recorded by the treating EP. Adherence was defined as participation in $\geq 80 \%$ of the available sessions (ie, at least four of the five sessions offered to patients), which is consistent with other research. ${ }^{19}$

\section{Measures}

The baseline questionnaire collected information on age, gender, marital status (married/de facto vs other), education (up to secondary school, diploma/certificate, university degree), and employment status (any paid employment, no paid employment, retired). Depression, fatigue, and quality of life were measured using the Centre for Epidemiologic Studies Depression Scale, ${ }^{20}$ The Worst Fatigue - Numeric Rating Scale, ${ }^{21}$ and the Assessment of Quality of Life-8D 
Utility Instrument, ${ }^{22}$ respectively. Psychological constructs derived from social cognitive theories, ${ }^{23,24}$ namely selfefficacy, positive outcome expectations, negative outcome expectations, social support, perceived physical environment, attitudes, confidence to change behavior, and goals and intentions, were assessed using scales developed and validated for this purpose as described elsewhere. ${ }^{15}$ Body mass index (BMI) was calculated from self-reported height and weight information collected in the baseline questionnaire. Waist circumference was self-measured using standardized instructions ${ }^{25}$ and a paper tape measure was provided by the research team. Information about the presence or absence of chronic health conditions (cardiovascular disease, diabetes, arthritis, depression, respiratory disease, and cancer) was obtained from the medical summary sheet provided by the primary care practice. Two experimental factors were also available for analysis: 1) intervention group (which intervention group the participant had been randomly allocated to, ie, face-toface counseling only $[\mathrm{F} 2 \mathrm{~F}]$ or telephone counseling after an initial face-to-face session [F2F+Tel]) and 2) group preference (which group the participant had expressed a preference for on the baseline questionnaire before they were randomized).

\section{Analysis}

Data were analyzed using R version 3.3 (R Core Team, 2016).

Descriptive statistics were calculated for selected variables. Multiple imputations were performed to impute missing values using chained equations and used as the basis of the analyses. We ran ten multiple imputations and used Rubin's method for pooling the results. ${ }^{26}$ First, we fitted univariate logistic regression models to estimate ORs and CIs for each potential predictor. Next, we fitted four multivariate logistic regression models for the sociodemographic, medical and health, psychological, and experimental group variables respectively, including all variables with no model reduction. Finally, we fitted a multivariate model using variables selected from all four groups on the basis of the strength of association between each predictor and response observed in the previously fitted models. Likelihood ratio tests were used to compare nested models with variables retained only if they were significant at the 0.05 level (globally for categorical variables). Linearity assumptions for continuous variables were assessed by plotting the empirical logits.

\section{Results \\ Participants}

The characteristics of the 132 patients (mean age 57, 72\% female, with a mean step count of 4,339) who were randomly allocated to receive physical activity counseling from an EP are summarized in Table 1.

\section{Adherence}

Of the 132 patients who were referred to an EP, 102 (77\%) were adherent: $91(69 \%)$ and eleven (8.3\%) participated in all, or all but one, of the sessions, respectively. Of the remainder, seven $(5.3 \%)$ patients participated in three sessions, seven $(5.3 \%)$ participated in two sessions, five (3.8\%) participated in one session, and eleven (8.3\%) did not participate in any session. The proportions classified as adherent did not differ statistically between the intervention groups ( $81 \%$ in the F2F group vs $73 \%$ in the F2F+Tel group; $P=0.31)$.

\section{Predictors of adherence}

Of the variables used in the analysis, $80 \%$ had less than 5\% missing data and $16 \%$ had between $5 \%$ and $10 \%$ missing data.

Table I Characteristics of the participants at baseline $(n=\mid 32)$

\begin{tabular}{|c|c|}
\hline Characteristics & $\begin{array}{l}\text { Mean } \pm \text { SD or } \\
\text { number }(\%)^{a}\end{array}$ \\
\hline Age (years) & $57 \pm 13$ \\
\hline \multicolumn{2}{|l|}{ Gender } \\
\hline Male & $37(28.0)$ \\
\hline Female & $95(72.0)$ \\
\hline \multicolumn{2}{|l|}{ BMI $\left(k g / m^{2}\right)$} \\
\hline Males & $33.4 \pm 4.9$ \\
\hline Females & $33.8 \pm 7.3$ \\
\hline \multicolumn{2}{|l|}{ Marital status } \\
\hline Married/de facto & $90(68.2)$ \\
\hline Not married & $40(30.3)$ \\
\hline \multicolumn{2}{|l|}{ Education } \\
\hline Up to secondary school & $43(32.6)$ \\
\hline Certificate or diploma & $58(43.9)$ \\
\hline University degree & $29(22.0)$ \\
\hline \multicolumn{2}{|l|}{ Employment status } \\
\hline Retired & $44(33.3)$ \\
\hline $\begin{array}{l}\text { No paid employment (household duties, } \\
\text { disability, unemployed, student) }\end{array}$ & $30(22.7)$ \\
\hline $\begin{array}{l}\text { Any paid employment (full-time, part-time, } \\
\text { self-employed, casual) }\end{array}$ & $56(42.4)$ \\
\hline \multicolumn{2}{|l|}{ Number of chronic diseases } \\
\hline$\leq \mathrm{I}$ chronic disease & $98(74.2)$ \\
\hline$\geq 2$ chronic diseases & $30(22.7)$ \\
\hline \multicolumn{2}{|l|}{ Type of chronic diseases ${ }^{b}$} \\
\hline Cardiovascular disease & $18(13.6)$ \\
\hline Diabetes & $27(20.5)$ \\
\hline Arthritis & $25(18.9)$ \\
\hline Depression & $32(24.2)$ \\
\hline Respiratory disease & $5(3.8)$ \\
\hline Cancer & $6(4.5)$ \\
\hline Pedometer-assessed daily step count & $4,339 \pm 1,534$ \\
\hline $\begin{array}{l}\text { Adjusted pedometer-assessed daily step count } \\
\text { (with imputation for "other activities") }\end{array}$ & $4,433 \pm 1,557$ \\
\hline
\end{tabular}

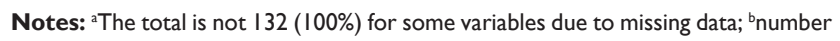
(\%) does not sum to $132(100 \%)$ as some participants had none of these conditions, while others had more than one of them.

Abbreviations: BMI, body mass index; $n$, number of participants. 
The group preference variable had the most missing values $(15 \%)$. Results of the univariate and multivariate logistic regression models using the pooled results from the multiple imputations are shown in Table 2. The results from both univariate and multivariate analyses were consistent with a complete case analysis on the original dataset. In the multivariate demographics model, there was no association between the odds of adherence and any of the nominated predictors, but the global $P$-value for the employment variable approached significance at the 0.05 level $(P=0.062)$ and the retired group had increased odds of adherence relative to the group not in paid employment (OR 5.37, 95\% CI 1.28-22.53, $P<0.05)$ after controlling for other demographic variables. The retired group also showed a statistically significant difference relative to those in any paid employment group (OR 4.56, 95\% CI 1.05-19.72, $P<0.05$ ). In the multivariate medical and health model, the odds of adherence decreased as the duration between referral and the initial counseling session increased (OR 0.95, 95\% CI 0.92-0.98, $P<0.01$ ) after controlling for other medical and health variables. In the multivariate psychological model, the odds of adherence increased as the positive outcome expectation score increased (OR 1.77, 95\% CI 1.04-3.00, $P<0.05$ ) after controlling for other psychological variables. In the final combined model, the odds of adherence were higher among patients who were retired (OR 5.84, 95\% CI 1.46-23.4, $P<0.05$ ) relative to those not in paid employment (employment was significant globally with $P<0.05$ ), but the retired group no longer showed a statistically significant difference relative to the any paid employment group (OR 2.43, 95\% CI $0.75-7.86, P=0.138)$. The odds of adherence increased as the positive outcome expectation score increased (OR 1.89, 95\% CI 1.12-3.18, $P<0.05)$ and decreased as the duration between referral and the initial counseling session increased (OR 0.95 per day, 95\% CI 0.92-0.98, $P<0.01$ ). There was no association between adherence and intervention group, or adherence and group preference in any of the models.

\section{Discussion}

This secondary analysis of data collected in a three-arm pragmatic randomized trial, which tested the effect of counseling by EPs (either face-to-face or predominately via telephone) on physical activity among insufficiently active primary care patients, showed that more than three quarters (77\%) of the referred patients participated in all, or all but one, of the counseling sessions offered to them. Only three factors predicted adherence: being retired (relative to not being in paid employment), having higher positive outcome expectations, and having a shorter wait between referral and the initial appointment.

The finding that the odds of adherence were higher among retired patients is consistent with the findings of a systematic review of retirees' experiences of and views on physical activity which identified three motives for physical activity: expected benefits for health and well-being, continuation of lifelong physical activity patterns, and the broader benefits of physical activity. ${ }^{27}$ Expected benefits for health and well-being included "stay[ing] ahead of the aging process" and "liv[ing] as long as possible", while the broader benefits included "a new personal challenge" (for men in particular) and "an opportunity for social interactions" (for women in particular). ${ }^{27}$ Accordingly, retired patients may be a particularly receptive group.

The finding that the odds of adherence to the physical activity counseling intervention delivered by EPs increased as the positive outcome expectations score increased is consistent with Social Cognitive Theory. ${ }^{28}$ It is also consistent with the identification of outcome expectations (expect benefit) as a "definitely associated factor" in a recent review of the correlates of participation in physical activity among adults. ${ }^{29}$ Consequently, it may be prudent for GPs to emphasize the benefits of physical activity when referring patients, particularly those who are in the pre-contemplation and contemplation stages of the Transtheoretical (Stages of Change) Model, ${ }^{30}$ to an EP. Tools that could be used to facilitate a discussion on the benefits of physical activity include the evidence-based behavior-change "Benefits of Physical Activity" handout, which is freely available from the Alberta Centre for Active Living website, ${ }^{31}$ or the "Choose Health: Be Active" resource, which is freely available from the Australian Government Department of Health website. ${ }^{32}$

The finding that the odds of adherence decreased as the duration (days) between referral and the initial counseling session increased has been reported previously. ${ }^{10}$ Given that patients may have delayed the first visit because of holiday plans, illness, or some other unexpected event, it may be difficult to minimize the time between the referral and the initial counseling session. Nevertheless, it may be prudent for EPs to proactively contact patients to book appointments rather than wait for patients to contact them.

To our knowledge, this is the first study to identify predictors of adherence to a physical activity counseling intervention for insufficiently active primary care patients delivered by EPs. There are, however, several limitations. First, the study design precludes conclusions about causality. Second, measures were limited to those collected in the 
Table 2 Predictors of adherence to a physical activity counseling intervention for insufficiently active primary care patients delivered by $\operatorname{EPs}(n=132)$

\begin{tabular}{|c|c|c|c|c|c|}
\hline & $\begin{array}{l}\text { Adherent } \\
\text { ( } \geq 4 \text { sessions) }\end{array}$ & $\begin{array}{l}\text { Not adherent } \\
\text { ( } \leq 3 \text { sessions) }\end{array}$ & $\begin{array}{l}\text { Unadjusted, } \\
\text { OR (CI) }\end{array}$ & $\begin{array}{l}\text { Models } s^{\mathrm{a}, \mathrm{b}} \text { from } \\
\text { grouped covariates } \\
\text { (sociodemographic, medical } \\
\text { and health, psychological, } \\
\text { and experimental group } \\
\text { factors), OR (Cl) }\end{array}$ & $\begin{array}{l}\text { Combined } \\
\text { model }^{\mathrm{a}} \text {, OR (Cl) }\end{array}$ \\
\hline \multicolumn{6}{|l|}{ Sociodemographic factors } \\
\hline & Mean (SD) & Mean $(S D)$ & & & \\
\hline Age & $\begin{array}{l}57.2(13.4) \\
n(\%)\end{array}$ & $\begin{array}{l}57.2(12.6) \\
n(\%)\end{array}$ & I $(0.97,1.04)$ & $0.97(0.93,1.02)$ & - \\
\hline \multicolumn{6}{|l|}{ Gender } \\
\hline Female & $73(72)$ & $22(73)$ & - & & - \\
\hline Male & $29(28)$ & $8(27)$ & $1.09(0.43,2.76)$ & I.I $14(0.42,3.09)$ & - \\
\hline \multicolumn{6}{|l|}{ Marital status } \\
\hline Married & $7 \mid(7 I)$ & $19(63)$ & - & & - \\
\hline Not Married & $29(29)$ & II (37) & $0.72(0.3, \mathrm{I} .7 \mathrm{I})$ & $0.63(0.24,1.66)$ & - \\
\hline \multicolumn{6}{|l|}{ Education } \\
\hline School & $34(34)$ & $9(30)$ & - & & - \\
\hline Certificate & $45(45)$ & $13(43)$ & $0.89(0.34,2.36)$ & $1.08(0.38,3.13)$ & - \\
\hline University & $2 I(2 I)$ & $8(27)$ & $0.68(0.23,2.06)$ & $0.84(0.25,2.8 I)$ & - \\
\hline \multicolumn{6}{|l|}{ Employment status } \\
\hline No paid employment & $20(20)$ & $10(33)$ & - & & - \\
\hline Any paid employment & $42(42)$ & $14(47)$ & $1.46(0.55,3.89)$ & $1.26(0.44,3.62)$ & $2.24(0.7,7.21)$ \\
\hline Retired & $38(38)$ & $6(20)$ & $3.14(0.99,9.98)$ & $5.37(1.28,22.53)^{d}$ & $5.84(1.46,23.4)^{\mathrm{d}}$ \\
\hline \multicolumn{6}{|l|}{ Medical and health factors } \\
\hline & Mean (SD) & Mean (SD) & & & \\
\hline Adjusted step count & $4,466.0(1,541.2)$ & $4,388.3(I, 635.1)$ & $I(I, I)$ & $\mathrm{I}(\mathrm{I}, \mathrm{I})$ & - \\
\hline Days to initial session & $18.5(14.5)$ & $28.7(18)$ & $0.95(0.93,0.98)^{\mathrm{e}}$ & $0.95(0.92,0.98)^{\mathrm{e}}$ & $0.95(0.92,0.98)^{\mathrm{e}}$ \\
\hline Depression & $12.8(9.8)$ & $16(12.3)$ & $0.98(0.94,1.01)$ & $0.98(0.93,1.03)$ & - \\
\hline Fatigue score & $\begin{array}{l}4.2(2.4) \\
n(\%)\end{array}$ & $\begin{array}{l}5(2.7) \\
n(\%)\end{array}$ & $0.87(0.73,1.03)$ & $0.96(0.77,1.2)$ & - \\
\hline \multicolumn{6}{|l|}{ BMI risk level } \\
\hline $\mathrm{BMI} \leq 30$ & $24(25)$ & $10(34)$ & - & - & - \\
\hline $\mathrm{BMI}>30$ & $73(75)$ & $19(66)$ & $\mathrm{I} .43(0.58,3.5)$ & $1.6(0.59,4.38)$ & - \\
\hline \multicolumn{6}{|l|}{ Chronic disease $^{c}$} \\
\hline No & $75(75)$ & $23(82)$ & & & \\
\hline Yes & $25(25)$ & $5(18)$ & $\mathrm{I} .4 \mathrm{I}(0.48,4.1)$ & $1.79(0.48,6.7)$ & - \\
\hline \multicolumn{6}{|l|}{ Psychological factors } \\
\hline & Mean (SD) & Mean (SD) & & & \\
\hline Goal setting & $45.2(30.3)$ & $40(30.2)$ & $1.01(0.99,1.02)$ & I $(0.98,1.02)$ & - \\
\hline Action plan & $2.6(I)$ & $2.3(I)$ & $1.39(0.92,2.1)$ & $1.32(0.78,2.22)$ & - \\
\hline Self-efficacy & $2.5(0.9)$ & $2.4(0.8)$ & I.II $(0.7,1.76)$ & $0.8(0.4 \mathrm{I}, \mathrm{I} .55)$ & - \\
\hline PosOE & $4.2(0.9)$ & $3.7(0.8)$ & $1.71(1.09,2.69)^{d}$ & $1.77(1.04,3)^{d}$ & $1.89(1.12,3.18)^{\mathrm{d}}$ \\
\hline $\mathrm{NegOE}$ & $3.6(0.9)$ & $3.6(0.8)$ & $1.07(0.66,1.74)$ & $0.91(0.52,1.6)$ & - \\
\hline Social support & $2.8(1.3)$ & $2.6(1.3)$ & $1.09(0.8,1.5)$ & $0.96(0.66,1.4 I)$ & - \\
\hline AQoL-8D & $74.7(18)$ & $81.5(21.6)$ & $0.98(0.96,1)$ & $0.99(0.96,1.01)$ & - \\
\hline \multicolumn{6}{|l|}{ Experimental group factors } \\
\hline Intervention group & $\mathrm{n}(\%)$ & n (\%) & & & \\
\hline $\mathrm{F} 2 \mathrm{~F}$ & $55(54)$ & $13(43)$ & - & & - \\
\hline $\mathrm{F} 2 \mathrm{~F}+\mathrm{Tel}$ & $47(46)$ & $17(57)$ & $0.65(0.29,1.5)$ & $0.6 \mathrm{I}(0.26,1.44)$ & - \\
\hline \multicolumn{6}{|l|}{ Group preference } \\
\hline $\mathrm{F} 2 \mathrm{~F}$ & $55(62)$ & $14(64)$ & - & & - \\
\hline $\mathrm{F} 2 \mathrm{~F}+\mathrm{Tel}$ & $8(9)$ & $2(9)$ & $0.54(0.1,2.89)$ & $0.49(0.09,2.6 \mathrm{I})$ & - \\
\hline Mailed & $7(8)$ & I (5) & $1.09(0.14,8.28)$ & $1.13(0.15,8.73)$ & - \\
\hline None & $19(21)$ & $5(23)$ & $0.85(0.27,2.68)$ & $0.82(0.26,2.59)$ & - \\
\hline
\end{tabular}

Notes: ${ }^{2}$ Complete case analysis, all covariates included in model; bgroup model estimate for chronic disease term could not be estimated; 'chronic disease indicates the

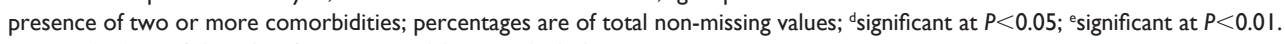

Abbreviations: AQoL-8D, Assessment of Quality of Life-8D Utility Instrument; BMI, body mass index; EPs, exercise physiologists; F2F, face-to-face counseling only; F2F+Tel, telephone counseling after an initial face-to-face session; n, number of participants; NegOE, Negative Outcome Expectations; PosOE, Positive Outcome Expectations. 
NewCOACH trial, some of which were self-reported rather than measured objectively (for example, BMI). Third, adherence may have been high because EPs were asked to initiate contact with patients to book appointments and the counseling sessions were provided free of charge to patients as part of the study. In addition, the response rate is unknown (because patients were informed about the study by GPs, practice nurses, receptionists, and via promotional materials located within the 50 primary care clinics involved in the recruitment process), but it is likely to have been low as recruitment was slower than expected. Although our small and relatively homogenous study sample (most participants were middle-aged, overweight/obese with one or more comorbidities) is unlikely to be representative of primary care patients in Australia in general, it is likely to be representative of the subgroup of patients that GPs will refer to an EP.

\section{Conclusion}

Physical activity counseling by EPs appears to be acceptable for insufficiently active primary care patients given that more than three quarters participated in all, or all but one, of the sessions offered to them. Being retired, positive outcome expectations, and having a shorter wait between referral and the initial appointment predicted adherence.

\section{Acknowledgments}

This work was supported by a National Health and Medical Research Council Project Grant (APP631062). The authors are grateful to the staff in the participating primary care clinics, the study participants, and the EPs who delivered the intervention. We acknowledge the contribution of Christine Edwards, Thomas Brookes, and Angela Booth for recruiting the primary care clinics, and Sandra Dowley for data entry. Our thanks to the research assistants who managed patient consent and screening within primary care clinics: Jenny Jackson, Amy Zhong, Lachlan McIntosh, Celine Corbisier De Meaultsart, and Brona Sparkes.

\section{Disclosure}

The authors report no conflicts of interest in this work.

\section{References}

1. World Health Organization. Global Status Report on Noncommunicable Diseases 2014. Geneva: World Health Organization; 2014. Available from: https://www.who.int/nmh/publications/ncd-status-report-2014/en/. Accessed November 14, 2018.

2. Orrow G, Kinmonth AL, Sanderson S, Sutton S. Effectiveness of physical activity promotion based in primary care: systematic review and metaanalysis of randomised controlled trials. BMJ. 2012;344:e1389.
3. Loprinzi PD, Beets MW. Need for increased promotion of physical activity by health care professionals. Prev Med. 2014;69:75-79.

4. Harris MF, Fanaian M, Jayasinghe UW, et al. What predicts patientreported GP management of smoking, nutrition, alcohol, physical activity and weight? Aust J Prim Health. 2012;18(2):123-128.

5. Clark RE, Mcarthur C, Papaioannou A, et al. "I do not have time. Is there a handout I can use?": combining physicians' needs and behavior change theory to put physical activity evidence into practice. Osteoporos Int. 2017;28(6):1953-1963.

6. Hébert ET, Caughy MO, Shuval K. Primary care providers' perceptions of physical activity counselling in a clinical setting: a systematic review. Br J Sports Med. 2012;46(9):625-631.

7. Morgan F, Battersby A, Weightman AL, et al. Adherence to exercise referral schemes by participants - what do providers and commissioners need to know? A systematic review of barriers and facilitators. BMC Public Health. 2016;16:227.

8. National Institute of Health and Clinical Excellence (NICE). Physical activity: exercise referral schemes. Public Health guideline [PH54]. Public Health Guidance 54. England: National Institute of Health and Clinical Excellence; 2014. Available from: https://www.nice.org. uk/guidance/ph54/chapter/What-is-this-guideline-about. Accessed November 14, 2018.

9. Stewart L, Dolan E, Carver P, Swinton PA. Per-protocol investigation of a best practice exercise referral scheme. Public Health. 2017;150: 26-33.

10. Pavey T, Taylor A, Hillsdon M, et al. Levels and predictors of exercise referral scheme uptake and adherence: a systematic review. J Epidemiol Community Health. 2012;66(8):737-744.

11. Cheema BS, Robergs RA, Askew CD. Exercise physiologists emerge as allied healthcare professionals in the era of non-communicable disease pandemics: a report from Australia, 2006-2012. Sports Med. 2014;44(7):869-877.

12. Franklin B, Fern A, Fowler A, Spring T, Dejong A. Exercise physiologist's role in clinical practice. Br J Sports Med. 2009;43(2):93-98.

13. Exercise and Sports Science Australia (ESSA). Accredited exercise physiologist scope of practice. Exercise and Sports Science Australia; 2018. Available from: https://www.essa.org.au/wp-content/uploads/2018/04/ AEP-scope-of-practice_2018.pdf. Accessed November 14, 2018.

14. James EL, Ewald BD, Johnson NA, et al. Referral for expert physical activity counseling: a pragmatic RCT. Am J Prev Med. 2017;53(4): 490-499.

15. James EL, Ewald B, Johnson N, et al. Efficacy of GP referral of insufficiently active patients for expert physical activity counseling: protocol for a pragmatic randomized trial (The NewCOACH trial). BMC Fam Pract. 2014;15:218.

16. Young MD, Plotnikoff RC, Collins CE, Callister R, Morgan PJ. Social cognitive theory and physical activity: a systematic review and metaanalysis. Obes Rev. 2014;15(12):983-995.

17. Conn VS, Hafdahl AR, Mehr DR. Interventions to increase physical activity among healthy adults: meta-analysis of outcomes. Am J Public Health. 2011;101(4):751-758.

18. World Medical Association. World Medical Association Declaration of Helsinki: ethical principles for medical research involving human subjects. JAMA. 2013;310(20):2191-2194.

19. Berg CJ, Ahluwalia JS, Cropsey K. Predictors of adherence to behavioral counseling and medication among female prisoners enrolled in a smoking cessation trial. J Correct Health Care. 2013;19(4):236-247.

20. Radloff LS. The CES-D scale: A self-report depression scale for research in the general population. Appl Psychological Measurement. 1977;1: 385-401.

21. Naegeli AN, Flood E, Tucker J, Devlen J, Edson-Heredia E. The patient experience with fatigue and content validity of a measure to assess fatigue severity: qualitative research in patients with ankylosing spondylitis (AS). Health Qual Life Outcomes. 2013;11:192.

22. Richardson J, Iezzi A, Khan MA, Maxwell A. Validity and reliability of the Assessment of Quality of Life (AQoL)-8D multi-attribute utility instrument. Patient. 2014;7(1):85-96. 
23. Bandura A. Social foundations of theory and action: A social cognitive theory. Englewood Cliffs, NY: Prentice-Hall; 1986.

24. Ajzen I. The theory of planned behavior. Organ Behav Hum Decis Process. 1991;50(2):179-211.

25. World Health Organization. Waist circumference and waist-hip ratio. Report of a WHOexpertconsultation. Geneva: World Health Organization; 2011. Available from: https://www.who.int/nutrition/publications/ obesity/WHO_report_waistcircumference_and_waisthip_ratio/en/. Accessed November 14, 2018.

26. Rubin DB. Multiple imputation for nonresponse in surveys. New York: John Wiley \& Sons; 1987.

27. Barnett I, Guell C, Ogilvie D. The experience of physical activity and the transition to retirement: a systematic review and integrative synthesis of qualitative and quantitative evidence. Int J Behav Nutr Phys Act. 2012;9(1):97.
28. Bandura A. Health promotion by social cognitive means. Health Educ Behav. 2004;31(2):143-164.

29. Choi J, Lee M, Lee JK, Kang D, Choi JY. Correlates associated with participation in physical activity among adults: a systematic review of reviews and update. BMC Public Health. 2017;17(1):356.

30. Prochaska JO, Velicer WF. The transtheoretical model of health behavior change. Am J Health Promot. 1997;12(1):38-48.

31. Alberta Centre for Active Living. Physical activity counselling toolkit Available from: https://www.centre4activeliving.ca/our-work/physicalactivity-counselling-toolkit/. Accessed November 14, 2018.

32. Brown WJ, Moorhead GE, Marshall AL. Choose Health: Be Active: a physical activity guide for older Australians. 2008. Available from: http://www.health.gov.au/internet/main/publishing.nsf/content/phdphysical-choose-health. Accessed November 14, 2018.

\section{Publish your work in this journal}

Patient Preference and Adherence is an international, peer-reviewed, open access journal that focuses on the growing importance of patient preference and adherence throughout the therapeutic continuum. Patient satisfaction, acceptability, quality of life, compliance, persistence and their role in developing new therapeutic modalities and compounds to optimize clinical outcomes for existing disease states are major areas of interest for the journal. This journal has been accepted for indexing on PubMed Central. The manuscript management system is completely online and includes a very quick and fair peer-review system, which is all easy to use. Visit http://www. dovepress.com/testimonials.php to read real quotes from published authors.

Submit your manuscript here: http://www.dovepress.com/patient-preference-and-adherence-journal 